\title{
Influence of complement depletion on sperm function in the female rabbit
}

\author{
J. M. Bedford*† and S. S. Witkin* \\ Departments of *Obstetrics and Gynaecology and $\nmid$ Cell Biology and Anatomy, Cornell University \\ Medical College, New York, New York 10021, U.S.A.
}

\begin{abstract}
Summary. Female rabbits were wholly depleted of complement by treatment with anticomplementary cobra venom factor (CVF) $36 \mathrm{~h}$ before mating. Complement depletion did not compromise occurrence of the acrosome reaction, as judged by sperm penetration of eggs collected 12-13 h post coitum. However, in CVF-treated females, significantly more spermatozoa had penetrated the egg vestments, more spermatozoa were present in flushings from the oviducts, and sometimes the uterus, than in control females mated to the same males. The results indicate that, although the acrosome reaction is unlikely to depend on complement activation, complement-dependent factors may exert a restrictive effect on spermatozoa after vaginal insemination of the normal female rabbit.
\end{abstract}

\section{Introduction}

Investigation of conception in mammals has been helped in the past two decades by development of reliable methods for superovulation, sperm collection, and in-vitro fertilization. There are still many unknowns, however, with respect to the factors that finally determine the functional state and fate of spermatozoa in the female tract. It is not clear what is the significance of the apparently excessive number of spermatozoa inseminated, how the tract reacts to antigens expressed by spermatozoa, what factors bring about capacitation there, or how sperm transport to the ampulla of the oviduct is regulated. It has also been unclear what regulates the acrosome reaction that spermatozoa must undergo in order to fertilize. In the invertebrates studied, the acrosome reaction is initiated by egg-coat substances which permit a calcium influx (Dan, 1954). There is no good evidence, however, that egg-derived factors must induce the acrosome reaction in eutherian mammals. It has seemed credible that other factors may regulate this in mammals, and as one possibility, it has been suggested that complement components found in follicular fluids may act at the sperm surface to initiate the membrane fusion that is the first step in the acrosome reaction (Cabot \& Oliphant, 1978).

The idea that follicular fluid complement may initiate the acrosome reaction is somewhat weakened by the fact that follicular fluid is not required for fertilization in vivo (Harper, 1970; Moore \& Bedford, 1978; Saling \& Bedford, 1981). Complement in tubal secretions might play such a role, but there is no clear picture as to which components of the complement system are represented throughout the female tract of the rabbit (Oliphant, Randall \& Cabot, 1977). However, the presence of antibody-coated rabbit ova in the oviduct evokes a mobilization of leucocytes which 
coat the zona pellucida within $3 \mathrm{~h}$, though generally not in rabbits previously given anticomplementary cobra venom factor (unpublished observations). Since leucocyte migration is probably a response to complement activation, this suggests that complement activation, via the classical pathway at least, can occur in the ampulla.

Based on the assumption that whole body depletion of complement is reflected in the lumen of the oviduct, we have used that approach to examine the role of complement activation in the process of fertilization.

\section{Materials and Methods}

New Zealand White rabbits weighing $3 \frac{1}{2} 4 \mathrm{~kg}$ were used to determine the effects of complement depletion on fertilization and, as a result of initial observations, on sperm distribution in the female tract.

Complement depletion was achieved in the rabbits by intravenous injection of an anticomplementary factor (CVF) prepared from cobra (Naja naja) venom according to the procedure of Ballow \& Cochrane (1969). Preliminary experiments using a haemolytic complement assay showed that any sample of $0.025-0.3 \mathrm{ml}$ of the CVF preparation containing $6 \mathrm{mg}$ protein $/ \mathrm{ml}$ would deplete rabbit serum of complement by $12 \mathrm{~h}$ after intravenous injection, and for at least 5 days thereafter. A dose of $0.2 \mathrm{ml}$ of that CVF preparation was used then throughout the subsequent study. Initial trials also showed that the fall in haemolytic complement was paralleled by a disappearance from the serum of a spermicidal effect (Chang, 1947) known to be produced by naturally occurring antisperm IgG in the presence of complement (Johnson, 1968; Hancock, 1979). The spermicidal effect is demonstrated easily by adding a dilute $\left(50 \times 10^{3} / \mathrm{ml}\right)$ suspension of motile ejaculated rabbit spermatozoa in Tyrode's solution (Tyrode, 1910) to an excess of serum, with examination in a phase-contrast microscope 2 min later. Independent assays performed using an enzyme-linked immunosorbent assay (ELISA) (Jackson, Sogn \& Kindt, 1982) showed no change in total IgG levels in the serum $36-48 \mathrm{~h}$ after CVF administration. Therefore, the disappearance of serum spermicidal activity after treatment with CVF served as a useful spot test of the complement status in each animal.

The experimental protocols involved natural mating of females given $0.2 \mathrm{ml} \mathrm{CVF} 36 \mathrm{~h}$ previously, and also mating of a series of untreated (control) female rabbits to the same individual males. Each female was mated with 3 stud bucks of high semen quality, within a few minutes. The matings of experimental and control females were generally interspersed with each other. The males were not used more than once every $48 \mathrm{~h}$. After mating, $50 \mathrm{i} . \mathrm{u}$. hCG were given intravenously to ensure ovulation. The females were killed by cervical dislocation, and blood was withdrawn by heart puncture. The abdomen was immediately opened and haemostats were placed on each uterotubal junction. The uterine horns were then flushed with Tyrode's solution via the cervix; subsequently, this was repeated 3-4 times with $0 \cdot 5 \%$ sodium dodecyl sulphate (SDS). The oviducts were flushed in both directions, first with Tyrode's solution and then with $0.5 \%$ SDS. Total numbers of spermatozoa in the tubal and uterine flushes were counted with a haemocytometer. Ova found in the first tubal flush were mounted immediately beneath wax-supported coverslips and examined in a phase-contrast microscope for numbers of perivitelline spermatozoa. When necessary, the follicular cells were removed first by treatment of eggs with $1 \%$ hyaluronidase (Sigma Type I) in Tyrode's solution and shaking in $2 \%$ sodium citrate. Counts were made of total numbers of spermatozoa within each perivitelline space. After fixation in acetic alcohol and staining in lacmoid, the eggs were also examined for evidence of penetration according to the presence of a sperm tail and sperm nucleus.

The results were evaluated statistically using the $\chi^{2}$ test for numbers of ova ovulated and the proportion of ova penetrated. Differences in sperm numbers in the perivitelline space, uterus and oviduct were assessed using the non-parametric Mann-Whitney test. 


\section{Results}

In the initial experiments, 2 normal females were injected intravenously with CVF, then mated with 3 males $36 \mathrm{~h}$ later and given hCG. The CVF-treated females seemed vigorous and healthy, and there was no reduction of the level of $\operatorname{IgG}$ in the serum as measured by an ELISA for rabbit immunoglobulin. Because serum taken at the time of death showed no significant haemolytic activity and no spermicidal activity, the females clearly were depleted of complement by the CVF. Eggs were flushed from the oviducts $14 \mathrm{~h}$ after mating. All had been penetrated $(9 / 9$ and $11 / 11)$, and between 6 and 25 perivitelline spermatozoa were present per egg. Furthermore, as judged by our previous experience, there appeared to be more spermatozoa swimming in the flushed medium around the mounted eggs than was usually seen in the course of such procedures. This preliminary result indicated that an absence of complement does not compromise sperm penetration of the eggs and so, by inference, occurrence of the acrosome reaction. However, since the findings gave the impression that complement depletion may have some influence on the distribution of spermatozoa in the female after mating, the study was extended to examine this aspect further.

Each of 14 females given CVF 36 h previously, and also 8 normal untreated females, were mated 3 times to the same 3 bucks. Among both groups at $12-13 \mathrm{~h}$ after hCG there was some variation in sperm numbers associated with the eggs recovered, and in the tract flushings, as might be expected. However, as shown in Table 1, in the CVF-treated females significantly more eggs

Table 1. Rates of egg penetration and sperm numbers in the uterus and oviducts, in untreated and complement-depleted female rabbits after mating with the same 3 bucks

\begin{tabular}{|c|c|c|c|c|c|c|}
\hline \multirow[b]{2}{*}{ Animal } & \multirow{2}{*}{$\begin{array}{c}\text { Time } \\
\text { after } \\
\text { hCG } \\
\text { (h) }\end{array}$} & \multicolumn{5}{|c|}{ Numbers of } \\
\hline & & $\begin{array}{c}\text { Ova } \\
\text { collected }\end{array}$ & $\begin{array}{c}\text { Ova } \\
\text { penetrated }\end{array}$ & $\begin{array}{l}\text { Perivitelline } \\
\text { sperm./ovum } \\
\text { (mean) }\end{array}$ & $\begin{array}{c}\text { Uterine } \\
\text { sperm. } \times 10^{6}\end{array}$ & $\begin{array}{c}\text { Tubal } \\
\text { sperm. } \times 10^{6}\end{array}$ \\
\hline \multicolumn{7}{|c|}{ CVF-treated females } \\
\hline 1 & 12 & 7 & 7 & 6 & $4 \cdot 5$ & $0 \cdot 26$ \\
\hline 2 & $13 \cdot 25$ & \multicolumn{3}{|c|}{ Ripe follicles - no ovulation } & & \\
\hline 3 & 13 & 13 & 13 & 14 & $7 \cdot 8$ & 0.96 \\
\hline 4 & $12 \cdot 5$ & 8 & 8 & 3 & $3 \cdot 6$ & 0.42 \\
\hline 5 & 13 & 3 & 3 & 20 & $10 \cdot 4$ & $0 \cdot 32$ \\
\hline 6 & $12 \cdot 5$ & 5 & 5 & 32 & $3 \cdot 8$ & 0.68 \\
\hline 7 & 13 & 9 & 9 & 11 & $4 \cdot 2$ & $0 \cdot 35$ \\
\hline 8 & $12 \cdot 5$ & \multicolumn{3}{|c|}{ Ripe follicles-no ovulation } & $3 \cdot 2$ & $0 \cdot 16$ \\
\hline 9 & 13 & 4 & 4 & 9 & $4 \cdot \overline{3}$ & 0.40 \\
\hline 10 & 12 & 8 & 8 & 11 & $8 \cdot 2$ & $0 \cdot 25$ \\
\hline 11 & $12 \cdot 5$ & 12 & 7 & 15 & $3 \cdot 4$ & $0 \cdot 21$ \\
\hline 12 & $12 \cdot 5$ & 2 & 2 & 30 & $12 \cdot 8$ & $0 \cdot 40$ \\
\hline 13 & 13 & \multicolumn{3}{|c|}{ Ripe follicles - no ovulation } & & \\
\hline 14 & $12 \cdot 5$ & 3 & 3 & $2 \cdot 0$ & $3 \cdot 2$ & $0 \cdot 28$ \\
\hline Mean & & 74 & $69^{*}$ & $12 \cdot 6 \dagger$ & $5 \cdot 8 \ddagger$ & $0.39 \S$ \\
\hline \multicolumn{7}{|c|}{ Untreated (control) females } \\
\hline 1 & 13 & 9 & 9 & $0 \cdot 3$ & $3 \cdot 2$ & 0.04 \\
\hline 2 & $12 \cdot 5$ & 5 & 2 & $1 \cdot 5$ & $2 \cdot 4$ & 0.092 \\
\hline 3 & 13 & 13 & 3 & $0 \cdot 1$ & 0.6 & 0.024 \\
\hline 4 & 12.5 & 11 & 2 & 0.2 & 2.9 & 0.006 \\
\hline 5 & 13 & 9 & 7 & 6 & 7.5 & 0.072 \\
\hline 6 & 13 & 7 & 7 & 8 & $5 \cdot 0$ & 0.025 \\
\hline 7 & $12 \cdot 5$ & 9 & 3 & $0 \cdot 2$ & 1.0 & 0.003 \\
\hline 8 & 12 & 2 & 0 & 0 & 0.9 & 0.01 \\
\hline Mean & & 65 & 33 & $2 \cdot 0$ & 2.9 & 0.038 \\
\hline
\end{tabular}

Compared with values for control females: ${ }^{*} P<0.005\left(\chi^{2}\right), \dagger P \sim 0.002$ (Mann-Whitney), $¥ P \sim 0.02$ (Mann Whitney), $\S P<0 \cdot 001$ (Mann-Whitney). 
were penetrated at $12-13 \mathrm{~h}$ after hCG $(P<0.005)$, there were more perivitelline spermatozoa $(P \sim$ $0.002)$ and more spermatozoa were flushed from the oviducts $(P<0.001)$. The number of spermatozoa recovered from the uterus at $12-13 \mathrm{~h}$ was also generally higher than that from the normal rabbits $(P \sim 0.02)$.

The results were variable, however, from female to female. In Rabbit 12, both eggs from one oviduct were covered with many motile spermatozoa to the extent that they rotated on the glass slide before being anchored by pressure from the coverslip. In Rabbits 11 and 14, there were very few perivitelline spermatozoa and not all eggs of Rabbit 11 were penetrated. Three of the females had not ovulated, although ripe follicles were present and oocytes released by puncture of these follicles had extruded the first polar body. In Rabbit 5, ova were found adhering to the surface of the ovary in what seemed unusually viscous cumulus oophorus with two other ripe follicles unruptured.

There were also 2 aberrant females not included in Table 1 . The serum of one showed normal spermicidal activity $48 \mathrm{~h}$ after CVF injection, but only $4 / 11$ eggs were penetrated at $13 \mathrm{~h}$ after hCG with a mean of less than one perivitelline spermatozoon. Conversely, one control female had no spermicidal activity in her serum when killed $12 \mathrm{~h}$ after hCG, and added motile spermatozoa were agglutinated in it by their tail surfaces. At $12.5 \mathrm{~h}$ the 2 eggs recovered were penetrated with 8 and 10 perivitelline spermatozoa, respectively. Thus, on the basis of the spermicidal activity of their serum, both females followed the general trend set in the experimental and control groups.

\section{Discussion}

CVF administration, in addition to depleting complement for about 5 days (Ballow \& Cochrane, 1969), can result in suppression of T cell-dependent antibody production (Martinelli, Matsuda \& Osler, 1978) and induce other short-lived haemodynamic effects (Ulevitch \& Cochrane, 1977). However, the present experiments were not performed until $36 \mathrm{~h}$ after CVF injection, thereby minimizing these other effects, as well as eliminating concern about a possible phospholipase $\mathrm{A}$ contaminant (Lachmann, Halbwachs, Gewurz \& Gewurz, 1976). The absence of haemolytic complement activity and also the spermicidal activity of the sera of treated rabbits that is complement dependent (Chang, 1947; Hancock, 1979), strongly implicate complement depletion as the central consequence of CVF administration in these experiments.

Although human cervical mucus possesses haemolytic complement activity (Price \& Boettcher, 1979), no complete picture exists as to the complement components at each level of the female tract (Oliphant et al., 1977; Schumacher, 1980). However, because complement-free conditions are employed in a variety of in-vitro capacitation/fertilization studies in different species (see Rogers, 1978) and in the present study fertilization occurred more readily in females depleted of complement $36 \mathrm{~h}$ before insemination, it is unlikely that the acrosome reaction depends on complement components acting at the surface of the spermatozoon, as suggested by Cabot \& Oliphant (1978). Although the acrosomal disruption induced by complement-dependent antibody may resemble the physiological acrosome reaction on occasion, this generally presents as a random breakdown of the peri-acrosomal plasma membrane, which may itself form vesicles, and of the outer acrosomal membrane (Bedford, 1969; Russo \& Metz, 1974; Roomans \& Afzelius, 1975). The available evidence raises an alternative possibility that the mammalian acrosome reaction is regulated in individual spermatozoa as a function of the process of capacitation (Bedford, 1983).

While complement may not be a key element in the onset of the acrosome reaction, our results suggest that complement-dependent factors play some role in sperm function in the female. The anticomplementary factors present in seminal plasma (Suarez \& Oliphant, 1982) are probably removed along with other seminal plasma components from spermatozoa as they swim in the uterus (Oliphant \& Brackett, 1973). It may therefore be important that the normal sperm surface can activate complement via the alternative pathway of the complement activation sequence (Clark \& Klebanoff, 1976; Witkin, Richards \& Bedford, 1983), because this suggests that the presence of 
specific antibody is not required for spermatozoa to initiate the activation of complement in the female tract.

The transport of spermatozoa into the rabbit female tract after insemination is not a random process, but usually follows a pattern characterized by rapid transport of a few spermatozoa to the oviduct, an intervening phase of low numbers in the uterus and oviduct, and a final slow build-up beginning at 3-4 h in the uterus and about $6 \mathrm{~h}$ post coitum in the oviduct (Overstreet \& Cooper, 1978). In complement-depleted females there were more spermatozoa than normal in the oviduct and often in the uterus, some 12-13 $\mathrm{h}$ after vaginal insemination. Complement depletion also resulted in a significantly higher proportion of eggs fertilized and in more spermatozoa in the perivitelline space of fertilized eggs than in normal females at $12-13 \mathrm{~h}$ after hCG. This implies that complement-mediated factors may normally exert some restrictive effect on spermatozoa in the female tract. This was also suggested in pilot studies performed for other reasons on rabbits with serum sickness (with B. Albini, B. K. Noble \& G. A. Andres, Department of Microbiology, University of Buffalo). Although precise sperm counts were not made, 2 rabbits inseminated vaginally in the terminal stages of serum sickness and essentially complement-depleted gave a similar strong impression of greater-than-normal numbers of spermatozoa in flushings from the uterus and oviducts. In these animals also, the serum had lost the spermicidal activity typical of normal individuals.

It remains to be established why more spermatozoa are able to reach the oviducts in complement-depleted female rabbits. Possible complement-dependent mechanisms that may militate against spermatozoa in the normal female rabbit could involve naturally occurring antibodies and leucocytes. IgG is bound to many spermatozoa flushed from the normal uterus, particularly to dead spermatozoa (Symons, 1967). However, whether this compromises the function of living spermatozoa is not clear, since they may bind IgG non-specifically via its Fc portion (Allen \& Bourne, 1978; Witkin, Shahani, Gupta, Good \& Day, 1980; Sethi \& Brandis, 1980), an interaction of unknown significance that would not result in complement fixation. Mammals also possess naturally occurring anti-sperm IgG in serum that does fix complement and kills spermatozoa by assembly of the membrane attack complex (Johnson, 1968; Hancock, 1979), but its transduction into the tract at significant levels is still questionable (McAnulty \& Morton, 1978). Leucocytes and sperm phagocytosis have long been recognized as sequelae to insemination (Austin, 1957; Bedford, 1965), and in the rabbit leucocytes appear after insemination in the vagina (Phillips \& Mahler, 1977), cervix (Tyler, 1977), and uterus (Soupart, 1970). A by-product of complement activation, the anaphylotoxin $\mathrm{C} 5 \mathrm{a}$, could be partly responsible for this leucocyte influx. It is easy to visualize that complement depletion may prevent leucocyte chemotaxis and their effects on spermatozoa. Arguing against leucocyte involvement as a main cause of the present results, however, are observations that the presence of leucocytes does not seem to compromise seriously the passage of spermatozoa through the cervical canal and on into the uterus (Taylor, 1982), and that leucocytes do not normally appear in the tubal lumen even after insemination. Moreover, spermatozoa are not the sole stimulus for the movement of leucocytes into the lumen of the noninfected tract. White cells invade the rodent uterus at the termination of oestrus whether or not spermatozoa are present (Austin, 1957), and they appear in the vagina after mating to vasectomized males (Phillips \& Mahler, 1977).

In these studies, 3 of the $14 \mathrm{CVF}$-treated females had not ovulated and one other had not completed ovulation by $12 \cdot 5-13 \cdot 25 \mathrm{~h}$ after hCG. This is not unprecedented according to the normal distribution reported by Harper (1960), but the proportion is higher than might be expected, indicating that complement-related factors could perhaps influence the follicular events that lead to ovulation (Espey, 1980).

This study was supported by NIH grants HD 16586 and HD 15528 . We thank Dr Susan Groschen, Department of Biostatistics, Sloan-Kettering Institute, New York, for help with the statistical analysis. 


\section{References}

Allen, G.J. \& Bourne, G.J. (1978) Interaction of immunoglobulin fragments with the mammalian sperm acrosome. J. exp. Zool. 203, 271-276.

Austin, C.R. (1957) Fate of spermatozoa in the uterus of the mouse and rat. $J$. Endocr. 14, 335-342.

Ballow, M. \& Cochrane, C.G. (1969) Two anticomplementary factors in cobra venom, hemolysis of guinea pig erythrocytes by one of them. J. Immun. 103, 944952.

Bedford, J.M. (1965) The effect of environment on phagocytosis of rabbit spermatozoa. J. Reprod. Fert. 9, 249-256.

Bedford, J.M. (1969) Morphological aspects of sperm capacitation in mammals. Adv. Biosci. 4, 35-50.

Bedford, J.M. (1983) Significance of the need for sperm capacitation before fertilization in eutherian mammals. Biol. Reprod. 28, 108-120.

Cabot, C. \& Oliphant, G. (1978) The possible role of immunological complement in induction of rabbit sperm acrosome reaction. Biol. Reprod. 19, 666-672.

Chang, M.C. (1947) The effects of serum on spermatozoa. J. gen. Physiol. 30, 321-335.

Clark, R.A. \& Klebanofi, S.J. (1976) Generation of neutrophil chemotactic agent by spermatozoa: role of complement and regulation by seminal plasma factors. $J$. Immun. 117, 1378-1386.

Dan, J.C. (1954) Studies on the acrosome. II. Acrosome reaction in starfish spermatozoa. Biol. Bull. mar. Biol. Lab. Woods Hole 107, 203-218.

Espey, L.L. (1980) Ovulation as an inflammatory reaction-a hypothesis. Biol. Reprod. 22, 73-106.

Hancock, R.J.T. (1979) Spermotoxic properties of IgG fractions from normal rabbit sera. Archs Androl. 2, 171-177.

Harper, M.J.K. (1960) The timing of ovulation in the rabbit following the injection of luteinizing hormone. $J$. Endocr. 22, 147-152.

Harper, M.J.K. (1970) Factors influencing sperm penetration of rabbit eggs in vivo. J. exp. Zool. 173, 47-62.

Jackson, S., Sogn, J.A. \& Kindt, T.J. (1982) Microdetermination of rabbit immunoglobulin allotypes by ELISA using specific antibodies conjugated with peroxidase or with biotin. J. Immunol. Meth. 48, 299309 .

Johnson, M.H. (1968) The characterization of a natural antibody in normal guinea-pig serum reacting with homologous spermatozoa. J. Reprod. Fert. 16, 503506.

Lachmann, P.J., Halbwachs, L., Gewurz, A. \& Gewurz, H. (1976) Purification of cobra venom factor from phospholipase A contaminant. Immunology 31, 961968.

Martinelli, G.P., Matsuda, T. \& Osler, A.G. (1978) Studies of immunosuppression by cobra venom factor. J. Immun. 121, 2043-2047.

McAnulty, P.A. \& Morton, D.B. (1978) The immune response of the genital tract of the female rabbit following systemic and local immunization. J. clin. Lab. Immunol. 1, 255-260.

Moore, H.D.M. \& Bedford, J.M. (1978) An in-vivo analysis of factors influencing the fertilization of hamster eggs. Biol. Reprod. 19, 879-885.

Oliphant, G. \& Brackett, B.G. (1973) Immunological assessment of surface change of rabbit spermatozoa undergoing capacitation. Biol. Reprod. 9, 404-414.
Oliphant, G., Randall, P. \& Cabot, C.L. (1977) Immunological components of rabbit fallopian tube fluid. Biol. Reprod. 16, 463-469.

Overstreet, J.W. \& Cooper, G.W. (1978) Sperm transport in the reproductive tract of the female rabbit. II. Sustained phase of transport. Biol. Reprod. 19, 115132.

Phillips, D.M. \& Mahler, S. (1977) Leukocyte emigration and migration in the vagina following mating in the rabbit. Anat. Rec. 189, 45-60.

Price, R.J. \& Boettcher, B. (1979) The presence of complement in human cervical mucus and its possible relevance to infertility in women with complement-dependent sperm-immobilizing antibodies. Fert. Steril. 32, 61-66.

Rogers, B.J. (1978) Mammalian sperm capacitation and fertilization in vitro: a critique of methodology. Gamete Res. 1, 165-223.

Roomans, G.M. \& Afzelius, B.A. (1975) Acrosome vesiculation in human sperm. J. submicrosc. Cytol. 7, 61-69.

Russo, J. \& Metz, C. (1974) The ultrastructural lesions induced by antibody and complement in rabbit spermatozoa. Biol. Reprod. 10, 293-308.

Saling, P.M. \& Bedford, J.M. (1981) Is sperm capacitation in vivo species specific? $J$. Reprod. Fert. 63, 119123.

Schumacher, G.F.B. (1980) Humoral immune factors in the female reproductive tract and their changes during the cycle. In Immunological Aspects of Infertility and Fertility Regulation, pp. 93-162. Eds D. S. Dhindsa \& G. F. B. Schumacher. Elsevier/North Holland, New York.

Sethi, K.K. \& Brandis, H. (1980) IgG Fc-binding receptors on spermatozoa. Eur. J. Immunol. 10, 964965.

Soupart, P. (1970) Leucocytes and sperm capacitation in the rabbit uterus. Fert. Steril. 21, 724-756.

Suarez, S.S. \& Oliphant, G. (1982) Interaction of rabbit spermatozoa and serum complement components. Biol. Reprod. 27, 473-484.

Symons, D.B.A. (1967) Reaction of sperm with uterine and serum globulin determined by immunofluorescence. J. Reprod. Fert. 14, 163-165.

Taylor, N.J. (1982) Investigation of a sperm-induced cervical leucocytosis by a double mating study in rabbits. J. Reprod. Fert. 66, 157-160.

Tyler, K.R. (1977) Histological changes in the cervix of the rabbit after coitus. J. Reprod. Fert. 49, 341-345.

Tyrode, M.V. (1910) Cited by Altman, P.L. \& Dittmer, D.S. (1972) Biology Data Handbook, Vol. I, p. 446. Fedn Am. Socs exp. Biol., Washington, D.C.

Ulevitch, R.J. \& Cochrane, C.G. (1977) Complementdependent hemodynamic and hematologic changes in the rabbit. Inflammation 2, $199-216$.

Witkin, S.S., Shahani, S.K., Gupta, S., Good, R.A. \& Day, N.K. (1980) Demonstration of IgG Fc receptors on spermatozoa and their utilization for the detection of circulating immune complexes in human serum. Clin. exp. Immunol. 44, 441-452.

Witkin, S.S., Richards, J.M. \& Bedford, J.M. (1983) Influence of epididymal maturation on the capacity of hamster and rabbit spermatozoa for complement activation. J. Reprod. Fert. 69, 517-521. 